\title{
Dedicated vs. shared resources in organizations: Modifying the Design Structure Matrix (DSM) to support consolidation decisions
}

\author{
Ali Yassine ${ }^{1}$, Nicolay Worren ${ }^{2}$, Tore Christiansen ${ }^{3}$ \\ ${ }^{1}$ American University of Beirut, ${ }^{2}$ Norwegian University of Life Sciences and Reconfig AS, ${ }^{3}$ Reconfig AS
}

\begin{abstract}
:
A key organization design principle is to group interdependent elements in the same clusters. This principle is the basis for the Design Structure Matrix (DSM), which can be used to automate the identification of clusters (e.g., teams). However, it may sometimes be necessary to depart from this design principle. We focus on one such situation, where the expected value of consolidating resources is deemed to be higher than the reduction in coordination costs from grouping resources in a modular cluster. We propose a set of criteria that can be used to assess consolidation potential as well as consolidation costs. We describe a solution for collecting subjective assessments of the value of consolidation and for incorporating this information into the DSM. This approach makes it possible to continue the use of the already established MDL clustering algorithm. We demonstrate the approach utilizing a simple data set with hypothetical values.
\end{abstract}

Keywords: DSM, departments, clustering, coordination, consolidation

\section{Introduction}

A key organization design principle is to group interdependent elements in the same clusters (e.g. teams and departments). This results in a design with semi-independent units (or modules) that is predicted to minimize coordination costs (Thompson, 1967), increase flexibility (Clark \& Baldwin, 2000; Sanchez, 1995) and enhance accountability by creating more focused units (Kilmann, 1983). This grouping principle assumes that one should optimize the design based on the existing set of interdependencies and that all units should have dedicated resources.

There are times, however, when one might consider departing from this principle. For example, consider an engineering manager responsible for a large development program with several teams. The project manager observes that there are people in several of the teams that perform weight and inertia analyses. He believes this type of analysis only requires generic skills, and wonders whether it would make sense to remove the role from the teams, and place it in a shared unit, one that can serve all the other teams. Or consider a manufacturing manager responsible for a plant that handles multiple product lines. She observes that there is a dedicated role for each product line which is responsible for ordering supplier parts and handling inbound logistics. She asks herself whether it would be cost effective to create a common logistics unit that serves all the product lines. 
The question of whether resources should be shared or dedicated to each unit is far from new: It was mentioned already in Urwick's (1937) classic description of key administrative problems. It is also acknowledged as a critical management decision by more recent authors. Within technology management, it is linked to the topic of product platforms based on shared components and the establishment of integration teams (Browning, 2009; Cusumano \& Nobeoka, 1998). In economics, it has been viewed as a pursuit of economies of scope by sharing assets, such as machines and equipment (Teece, 1980). In strategic management, it is related to discussions of how firms achieve synergy across units (Ansoff, 1968). In organizational theory, it is discussed in relation to how firms achieve knowledge transfer and resource sharing (Ensign, 2004; van Wijk et al., 2008). However, with the exception of the macro-level approach used by economists to compare the costs of different organizations (with or without shared resources [e.g., Hill et al., 1992]), we are not aware of any structured or analytical methods that can support individual managers in making decisions about consolidation of resources.

The Design Structure Matrix (DSM) is a tool that is used to document and automatically cluster interdependent elements, including roles in organizations (Eppinger \& Browning, 2012). There do exist DSM methods that make exceptions to the grouping criterion mentioned above. For example, Sharman and Yassine (2004) suggested forming a new module type by splitting a matrix and placing so called "bus" elements outside of clusters. Also, Otto et al. (2020) suggested using field constraints that place constraints on clustering choices. Finally, Micaëlli et al., (2011) suggested the use of skill-DSMs to identify potential skill networks within the organization. As we will describe below, these examples are related - but not identical - to resource consolidation. In any case, it is natural to build on the DSM rather than develop a new tool, as the DSM is intended to support grouping decisions and as it is flexible enough to accommodate adjustments and extensions. Hence the key questions that we address in this paper is how the DSM methodology can be extended to support grouping in situations where some elements may be consolidated outside of interdependent clusters.

\section{Background}

From a cost perspective, it may sometimes be more efficient to share resources across units rather than dedicating resources to each unit. In economics, this is referred to as economies of scope, which is based on the notion of "sub-additivity" of the cost function. In a situation with two products, ( $a$ and $b$ ), economies of scope are said to exist when the cost of producing both products together is lower, compared to producing them separately; formalized as:

$$
C(a, b)<C(a)+C(b)(\text { Teece, } 1980)
$$

The concept of economies of scope was originally intended to describe a situation where physical assets or equipment could be shared between two or more product lines, thereby reducing costs (assuming that there was excess capacity). However, in strategic management, it is typically interpreted in a broader fashion, and equated to "horizontal synergy" in firms. Horizontal synergy may be achieved not only due to cost reductions from asset sharing, but also from increased revenue or return on investment by sharing 
Dedicated vs. shared resources in organizations: Modifying the Design Structure Matrix (DSM) to support consolidation decisions

resources. In this literature, the term "resources" itself is also interpreted broadly and may include intangible resources such as knowledge, culture, and even brand reputation (Barney, 1991).

Even when there are potential benefits from consolidating certain resources, there are also potential downsides that should be considered before a final decision is made. First, there is an implementation cost associated with consolidation. A new unit will need to be established, employees will need to be transferred to this unit, new work processes may need to be defined, IT systems be installed, and service level agreements established. Secondly, consolidation will usually increase coordination costs. If we consider a single role to be consolidated, and assume that it was originally grouped with other team roles based on work process interdependencies, removing the role from the team and placing it in another unit will obviously increase the coordination costs for the unit where it was originally placed. However, it may also increase coordination costs for the overall organization (Zhou, 2013). The reason is that when the role becomes a shared resource, it implies that several internal units will need to reach agreement about how requests are going to be prioritized. Even when the role has been defined and agreed to by different units (typically considered as internal clients), they may still need to invest time in coordinating with each other and monitor decisions that other units are making regarding the role. Such "transaction hazards" are extensively discussed in the literature on transaction cost theory (Teece, 1980; Williamson, 1975). In addition, as shared units typically are incentivized to reduce cost and standardize their work processes, it will often lead to decreased service quality for the internal users of the services. The implication is that coordination costs and service quality may in some cases offset the potential economies of scope that one could derive from consolidating the resource. When estimating the potential value of consolidation, we thus need to take both the benefits and the costs into consideration.

In a separate project, we review the various criteria that may be relevant to make a consolidation decision, such as projected benefits from increased utilization, standardization, and learning. We list these criteria below but mainly focus on how the DSM can support such decisions.

\section{Existing methods}

As mentioned, there already exists principles and methods for making exceptions to the main clustering principle in the Design Structure Matrix (DSM). The most prominent is the concept of a "bus". A bus has been defined as an element that interact with most other elements (Browning, 2009) or as a "system level integrating component" (Sharman \& Yassine, 2004, p. 41) (Figure 1). A typical example in an engineering project would be the integration team, which communicates with almost all other teams in the project (McCord and Eppinger, S. D., 1993). Such teams may be defined at multiple levels. Lower level integration teams together constitute systems teams at the project or program level (Browning, 2009) (There may also exist weak or auxiliary buses that have strong connections to a subset of other elements, or weak connections to many elements [Sharman \& Yassine, 2004].) 


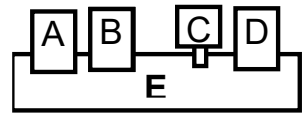

(a) Physical Dependency

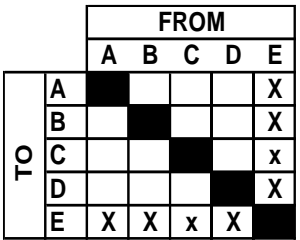

(b) DSM Model

Figure 1: A pictorial representation of a "bus" element and corresponding DSM model. Adopted from Sharman \& Yassine (2004).

There do exist algorithms that successfully identify buses in DSMs (Yu et al., 2007). Once a bus has been identified in a DSM, it will be identical to a consolidated unit as defined here: A consolidated unit is also one that has interactions with multiple other units. However, the criteria and the process for defining a consolidated unit are different. As described above, decisions about consolidation are not necessarily based on existing task interdependencies, but on the potential value from consolidation. For example, if there are three departments in an organization, and each department has a team that provides IT support; these teams may be completely isolated today and have no interactions with each other. Nonetheless, they might still benefit from being grouped together (to reap the benefits of increased utilization, standardization, or learning). For this reason, consolidation decisions require the use of additional information about the elements; whereas identification of buses is strictly based on the information contained within the DSM.

Another related concept is that of "field separation" (Otto et al., 2020; Sanaei et al., 2016). Fields define boundaries or constraints that have consequences for how elements are grouped in a physical product to avoid interferences between components or from external forces such as magnetic interference. For example, high versus low voltage may constitute different fields. The product architecture may need to be divided into "zones" to avoid combining components with high and low voltage in the same module. To define such boundaries, each component is first defined based on its value according to the field. Sanaei et al. (2016) developed an algorithm that can be then be employed to group components based on interdependencies, while separating those that are incompatible based on the field values. While field separation so far has only been applied to physical products, a similar concept, functional conflict, was proposed in Worren \& Pope (2021) as a principle for making organization design decisions. Functional conflict is said to exist when the function (or goal) of a role conflicts with that of another role in the same unit, for example, due to conflicts of interests or incompatible work processes. Both field separation and functional conflict imply that some elements should be separated from each other, rather than integrated. They also imply that one makes use of other criteria (i.e., constraints) compared to the criterion traditionally used in DSM (i.e., reduction of coordination costs). Yet these concepts still differ from consolidation as defined here. Consolidation is mainly driven by perceived positive benefits of grouping some elements (e.g., roles) together in a common or shared unit; it is not based on negative effects of the current grouping of roles or conflicting functions within a unit. 
Dedicated vs. shared resources in organizations: Modifying the Design Structure Matrix (DSM) to support consolidation decisions

\section{Proposed Approach}

The proposed approach is a two-step approach that begins with assessing the consolidation potential for candidate roles or functions. Then, a DSM-based method is utilized to perform the analysis.

\subsection{Assessing consolidation potential}

Consolidation potential must be evaluated in each particular case. The first step is to identify candidate roles or functions for consolidation. This may be a straightforward task if one is primarily interested in standard, administrative roles (e.g., Accounting, IT, HR, procurement, facility services, etc.). These are usually well defined and easy to identify based on position titles. It is more challenging to identify consolidation potential in projects or in organizations where the roles are new or less well defined. In such situations, it may be necessary to first interview or survey members of the organization to identify the key functions that are performed and consider whether similar functions are performed by roles in several units. These roles may then be candidates for consolidation, which may be evaluated based on the criteria in Table 1 .

Table 1. Criteria favoring consolidation of resources

\begin{tabular}{ll}
\hline \hline Criteria & Benefits that may be achieved \\
\hline $\begin{array}{l}\text { Need for learning and functional } \\
\text { specialization }\end{array}$ & $\begin{array}{l}\text { People who are organized in the same unit may more easily } \\
\text { share knowledge and learn from each other }\end{array}$ \\
$\begin{array}{l}\text { Need for consistency of } \\
\text { methods and approaches across } \\
\text { units }\end{array}$ & $\begin{array}{l}\text { People who are organized in the same unit will more easily } \\
\text { share knowledge and coordinate with each other to achieve } \\
\text { consistent products or services }\end{array}$ \\
$\begin{array}{l}\text { Low or uneven resource } \\
\text { utilization }\end{array}$ & $\begin{array}{l}\text { The average resource utilization will increase if resources } \\
\text { that are not utilized fully over time by individual units are } \\
\text { pooled and shared across units }\end{array}$ \\
$\begin{array}{l}\text { Task generality } \\
\text { (standardization) }\end{array}$ & $\begin{array}{l}\text { When tasks are (or can become) general or standardized, it is } \\
\text { more efficient to organize the roles that perform the tasks in } \\
\text { a common unit (e.g., in order to re-use tools and methods). }\end{array}$ \\
\hline
\end{tabular}

Different methods will need to be used to collect data related to each of the criteria listed in Table 1. The need for learning and functional specialization may perhaps be evaluated by the employees themselves, for example, in a survey. The need for consistency of methods should be evaluated based on the market that is served and the organization's strategy. Some organizations need to adapt to local needs, while others serve large markets with standard products, and will benefit more strongly from internal consistency and standardization. As for time utilization, there may already exist internal data of the time spent on different work processes. If not, it is possible to distribute a time utilization survey 
to collect such data. The extent to which the tasks that are performed are specific to each internal unit or are more general may be evaluated based on interviews with representatives of the different units (who in a future organization may become "clients" of a common unit that is established as the result of the consolidation). The final element is to estimate the implementation costs. The general tendency is to underestimate the costs. One approach to develop more realistic elements is to use reference class forecasting (Flyvbjerg, 2008). The key idea is not to use internally developed estimates, but identify similar projects performed in other organizations, and obtain information about the outcomes of those projects.

\subsection{Adapting the DSM to support consolidation decisions}

If we assume that the consolidation potential can be assessed according to the proposed criteria (cf. Table 1), the next question is how this information can be integrated into the DSM. The objective is to augment or modify the DSM data itself, the clustering metric, or the clustering algorithm to be able to incorporate the consolidation of resources into the DSM analysis. We propose four different potential approaches:

1. "Freeze" or exclude the relevant roles from the clusters

2. Deprioritize the interdependencies associated with the relevant roles

\section{Filter out related interdependencies}

4. Modify the minimum description length (MDL) metric used in the clustering algorithm

As an example, consider a simple organization with six employees: Four engineers and two IT support staff, as shown in Figure 2a. In terms of the work processes shown in Figure 2a, the natural solution would be to combine Engineers 1 and 2 with IT employee 1 and Engineers 2 and 4 with IT employee 2 (see Figure 2b). However, let us assume that there is a positive consolidation potential for IT roles due to the fact that the two IT employees have been asked to closely align their working methods, re-use the same solutions, and exchange information (cf. Table 1).

There are in principle four different approaches that may be taken in the subsequent DSM analysis. The first is to simply exclude the relevant roles from the analysis (Figure 2c). That is, remove the IT employees from the DSM and deal with the rest of the DSM. This approach is very easy, and it reduces the size of the DSM under investigation. Obviously, for this method to work, we need to be able to identify the relevant roles to be consolidated by using a tag like "IT", or pick them individually. The downside of this approach is that the algorithm will not group the roles that are to be consolidated. This may not be a concern if there are few interdependencies between them to begin with or if one foresees that entirely new work processes will be created once these roles are transferred to a shared unit. However, there will in many cases be some level of interaction between the roles, which may be the basis for grouping the roles within the shared unit that is to be established. 
Dedicated vs. shared resources in organizations: Modifying the Design Structure Matrix (DSM) to support consolidation decisions

Another solution is to keep the roles in the DSM but to de-prioritize the interdependencies between them and the rest of the DSM elements when optimizing the data. If the algorithm takes the strength of the interdependencies into account, one can assign a penalty to the relevant segment (the IT roles in this cases), either by reducing the values in the cells corresponding to these roles or by increasing the values in cells corresponding to all roles outside the relevant segment. The circled cells in the DSM of Figure $3 b$ represent deprioritized interdependencies (i.e., the values have been reduced in strength). This adjustment will make it possible to proceed with the optimization with no changes required to the algorithm itself (Figure 3c). However, it does not result in a reduction in the size of the DSM as in the first method (Figure 2a-c). Similar to method 1, we need to be able to identify the relevant roles to be consolidated.

(a) Initial mapping of roles and work process interdependencies

\begin{tabular}{|c|c|c|c|c|c|c|c|}
\hline & & A & B & C & D & $\mathrm{E}$ & $\mathrm{F}$ \\
\hline Engineer 1 & A & & & 3 & & 3 & \\
\hline Engineer 2 & B & & & & 3 & & 3 \\
\hline Engineer 3 & C & 3 & & & & 3 & \\
\hline Engineer 4 & D & & 3 & & & & 3 \\
\hline IT support 1 & $E$ & 3 & & 3 & & & \\
\hline IT support 2 & $\mathrm{~F}$ & & 3 & & 3 & & \\
\hline
\end{tabular}

(b) Grouping based on interdependencies only

\begin{tabular}{ll|l|l|l|l|l|l|} 
& & \multicolumn{1}{c}{ A } & \multicolumn{1}{c|}{ C } & \multicolumn{1}{c|}{ E } & \multicolumn{1}{c|}{ B } & \multicolumn{1}{c|}{ D } & F \\
\hline Engineer 1 & A & & 3 & 3 & & & \\
\hline Engineer 3 & C & 3 & & 3 & & & \\
\hline IT support 1 & E & 3 & 3 & & & & \\
\hline Engineer 2 & B & & & & & 3 & 3 \\
\hline Engineer 4 & D & & & & 3 & & 3 \\
\hline IT support 2 & F & & & & 3 & 3 & \\
\hline
\end{tabular}

(c) Grouping after "freezing" the two IT roles to be consolidated

Engineer 1

Engineer 3

Engineer 2

Engineer 4

IT support 1

IT support 2

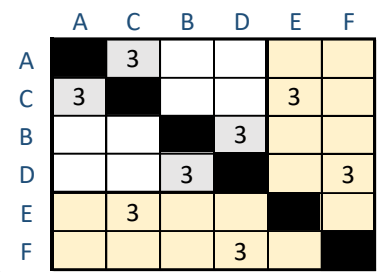

Figure 2a-c. Method 1: "Freeze" (exclude) roles that need to be consolidated $(1=$ Least important; $3=$ Most important). (a) Initial mapping of roles and work process

interdependencies

\begin{tabular}{|c|c|c|c|c|c|c|c|}
\hline Engineer 1 & $A$ & & & 3 & & 3 & \\
\hline Engineer 2 & B & & & & 3 & & 3 \\
\hline Engineer 3 & $\mathrm{C}$ & 3 & & & & 3 & \\
\hline Engineer 4 & $D$ & & 3 & & & & 3 \\
\hline IT support 1 & $\mathrm{E}$ & 3 & & 3 & & & \\
\hline IT support 2 & $\mathrm{~F}$ & & 3 & & 3 & & \\
\hline
\end{tabular}

(b) Assignment of penalty to IT roles

\begin{tabular}{|l|}
\hline Engineer 1 \\
\hline Engineer 2 \\
\hline Engineer 3 \\
\hline Engineer 4 \\
\hline IT support 1 \\
\hline IT support 2 \\
\hline
\end{tabular}

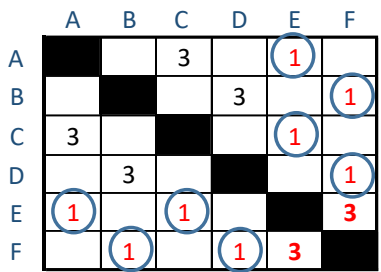

(c) Likely grouping using existing algorithm

\begin{tabular}{|l|}
\hline Engineer 1 \\
\hline Engineer 3 \\
\hline Engineer 2 \\
\hline Engineer 4 \\
\hline IT support 1 \\
\hline IT support 2 \\
\hline
\end{tabular}

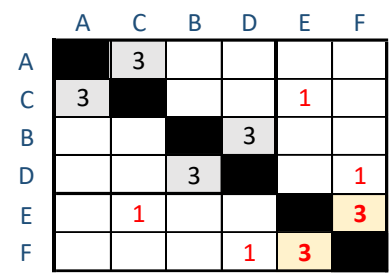

Figure 3a-c. Method 2: Assign penalty to a segment (i.e., the roles that need to be consolidated)

A third approach is possible if one has information about the work processes or activities that different roles contribute to. One can then filter out interdependencies related to, say "IT support" or "IT development", and run the optimization on the remaining data (see Figure 4a-c). Note that unlike Method 1, it does not require that one "freezes" the roles 
(elements) themselves, only that one filter out some of the interdependencies (i.e., the ones related to processes that may be consolidated). As with Method 2, it does not require any adjustment or modification of the clustering algorithm. However, it will obviously only produce the desired effect if the roles are focused and do not contribute equally strongly to multiple processes inside and outside of the scope of the planned consolidation. This method also requires us to be able to identify the relevant roles to be consolidated by using a tag like "IT" or to pick them individually.

(a) Initial mapping of roles and work process interdependencies

\begin{tabular}{|c|c|c|c|c|c|c|c|}
\hline & & A & B & C & D & E & $\mathrm{F}$ \\
\hline Engineer 1 & A & & & 3 & & 3 & \\
\hline Engineer 2 & B & & & & 3 & & 3 \\
\hline Engineer 3 & $\mathrm{C}$ & 3 & & & & 3 & \\
\hline Engineer 4 & $\mathrm{D}$ & & 3 & & & & 3 \\
\hline IT support 1 & $\mathrm{E}$ & 3 & & 3 & & & \\
\hline IT support 2 & $\mathrm{~F}$ & & 3 & & 3 & & \\
\hline
\end{tabular}

(b) Filter out interdependecies for the IT roles

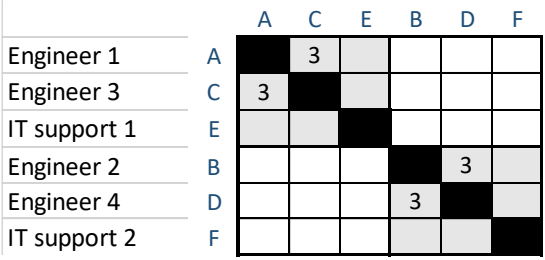

(c) Grouping after "Filtering out" dependencies for two IT roles to be consolidated

\begin{tabular}{|l|}
\hline Engineer 1 \\
\hline Engineer 3 \\
\hline Engineer 2 \\
\hline Engineer 4 \\
\hline IT support 1 \\
\hline IT support 2 \\
\hline
\end{tabular}

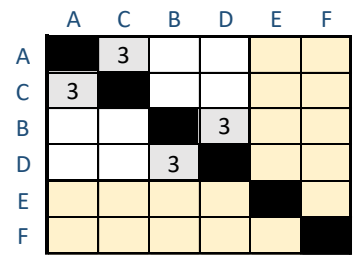

Figure 4a-c. Method 3: Filter out related interdependencies for roles that need to be consolidated (a) Initial mapping of roles and work process interdependencies

Engineer 1

Engineer 2

Engineer 3

Engineer 4

IT support 1

IT support 2

\begin{tabular}{|c|c|c|c|c|c|c|}
\hline & A & $B$ & C & $\mathrm{D}$ & $\mathrm{E}$ & $\mathrm{F}$ \\
\hline A & & & 3 & & 3 & \\
\hline B & & & & 3 & & 3 \\
\hline$C$ & 3 & & & & 3 & \\
\hline$D$ & & 3 & & & & 3 \\
\hline$E$ & 3 & & 3 & & & \\
\hline F & & 3 & & 3 & & \\
\hline
\end{tabular}

(b) Grouping based on interdependencies only (this results in a specific MDL score)

\begin{tabular}{|l|}
\hline Engineer 1 \\
\hline Engineer 3 \\
\hline IT support 1 \\
\hline Engineer 2 \\
\hline Engineer 4 \\
\hline IT support 2 \\
\hline
\end{tabular}

\begin{tabular}{|c|c|c|c|c|c|}
\hline A & C & $\mathrm{E}$ & B & D & $\mathrm{F}$ \\
\hline A & 3 & 3 & & & \\
\hline 3 & & 3 & & & \\
\hline 3 & 3 & & & & \\
\hline B & & & & 3 & 3 \\
\hline D & & & 3 & & 3 \\
\hline$F$ & & & 3 & 3 & \\
\hline
\end{tabular}

(c) Likely grouping with modified MDL clustering algorithm (this results in a lower MDL score)

Engineer 1

Engineer 3

Engineer 2

Engineer 4

IT support 1

IT support 2

\begin{tabular}{|c|c|c|c|c|c|c|}
\hline & $A$ & C & B & D & $E$ & $\mathrm{~F}$ \\
\hline A & & 3 & & & 3 & \\
\hline C & 3 & & & & 3 & \\
\hline B & & & & 3 & & 3 \\
\hline D & & & 3 & & & 3 \\
\hline $\mathrm{E}$ & 3 & 3 & & & & \\
\hline$F$ & & & 3 & 3 & & \\
\hline
\end{tabular}

Figure 5a-c. Method 4: Modify the MDL metric to incorporate the impact of consolidation

The fourth approach, shown in Figure 5a-c, does require a modification to the clustering algorithm. Figure 5c illustrates how a modified MDL clustering algorithm would consolidate the two IT support staff. This proposed solution (in Figure 5c) provided an improved MDL value, compared to Figure 5b, where consolidation is not considered. Therefore, one can modify the MDL clustering metric by adding a term to account for the potential benefit of consolidation. We refer to this term as "Type 3 mismatch" or "consolidation mismatch". The consolidation mismatch set describes the number of roles that need to be consolidated but are not actually consolidated. The new MDL metric 
Dedicated vs. shared resources in organizations: Modifying the Design Structure Matrix (DSM) to support consolidation decisions

becomes as shown in Equation (2), where the $\mathrm{f}_{1}, \mathrm{f}_{2}, \mathrm{f}_{3}, \mathrm{f}_{4}$ represent the model description length (defining or encoding the number of clusters and their elements, in addition to the different roles that need to be consolidated), the mismatch type 1 description length (encoding the difference between real DSM data and the hypothesized DSM for marks inside each of the clusters), the mismatch type 2 description length (encoding the difference between real DSM data and the hypothesized DSM for marks between the clusters), and the mismatch type 3 description length (encoding any consolidation violations), respectively. The $\mathrm{w}_{\mathrm{i}}$ represent the weights on the various model parts. The advantage of this approach is that all the roles are considered by the clustering algorithm; however, this would require additional computations and MDL modification.

$$
f_{D S M}(M)=w_{1} f_{1}+w_{2} f_{2}+w_{3} f_{3}+w_{4} f_{4} \quad \text { (Adopted from Yu et al., 2007) }
$$

As an example, consider the DSM in Figure 6a, which maps out the initial roles and responsibilities in a small organization. Using the modified MDL metric, produces the four DSMs in Figures 6b-e. Namely, Figure 6b shows the ideal DSM assumed by the model description length in the MDL metric; it assumes 2 perfectly populated clusters and that IT support 1 and 2 are potential for consolidation. The mismatch data sets shown in Figures $6 c-e$ presents any deviation from this assumed perfect clustering arrangement (assumed in Figure 6b). For example, Figure $6 \mathrm{c}$ shows that the actual clusters are not perfect clusters and they do not contain the specified marks in the DSM. Similarly, Figure 6d shows that these two clusters are not perfectly independent (as assumed in Figure 6b) and they are related by the specified marks in the DSM. Finally, Figure 6e shows that the two IT support staff should have been consolidated into a separate cluster, but since that did not happen, the relation between the IT support staff became a mismatch as shown in the DSM.

\section{Summary and Conclusion}

The benefits that one derives from consolidating resources (e.g., roles) will sometimes offset the reduction in coordination costs that one can gain by clustering roles together. We have discussed four different ways in which we can enhance DSM clustering techniques to allow for the analysis of resource consolidation. Further work needs to be conducted to verify which of these methods is the most effective and to operationalize the method in existing DSM software. 
(a) Initial mapping of roles and work process interdependencies

Engineer 1

Engineer 2

Engineer 3

Engineer 4

IT support 1

IT support 2

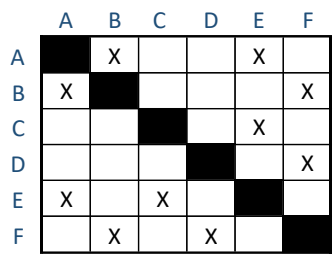

(b) DSM based on model description

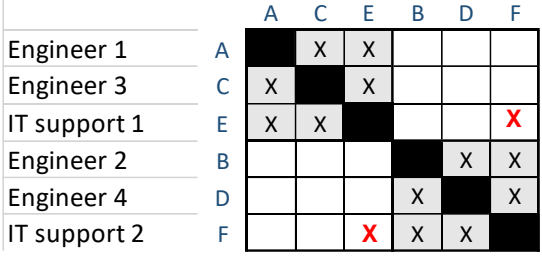

(c) Type 1 mismatch (hypothesized marks in the model description (b) that do not exist in the real data set (a)

\begin{tabular}{|c|c|c|c|c|c|c|}
\hline & & A & C & $\mathrm{E}$ & B & D \\
\hline Engineer 1 & A & & $x$ & & & \\
\hline Engineer 3 & C & $x$ & & & & \\
\hline IT support 1 & E & & & & & \\
\hline Engineer 2 & B & & & & & $\mathrm{x}$ \\
\hline Engineer 4 & D & & & & $\mathrm{x}$ & \\
\hline IT support 2 & $\mathrm{~F}$ & & & & & \\
\hline
\end{tabular}

(d) Type 2 mismatch (real marks that the hypothesized model misses)

\begin{tabular}{|l|}
\hline Engineer 1 \\
\hline Engineer 3 \\
\hline IT support 1 \\
\hline Engineer 2 \\
\hline Engineer 4 \\
\hline IT support 2 \\
\hline
\end{tabular}

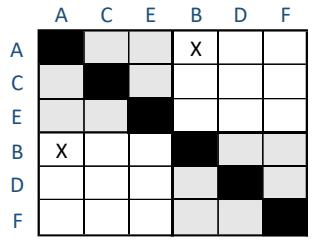

(e) Type 3 mismatch (consolidation violations; elements in the DSM that should have been consolidated, but which were not)

\begin{tabular}{|l|}
\hline Engineer 1 \\
\hline Engineer 3 \\
\hline IT support 1 \\
\hline Engineer 2 \\
\hline Engineer 4 \\
\hline IT support 2 \\
\hline
\end{tabular}

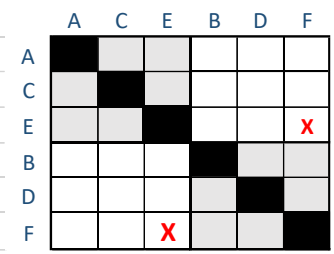

Figure 6a-e. Method 4: The use of mismatched data sets

\section{References}

Ansoff, I. (1968). Corporate Strategy: An Analytic Approach to Business Policy For Growth And Expansion. Penguin.

Barney, J. (1991). Firm Resources and Sustained Competitive Advantage. Journal of Management, 17(1), 99-120.

Browning, T. R. (2009). Using the Design Structure Matrix to Design Program Organizations. In A. P. Sage \& W. B. Rouse (Eds.), Handbook of Systems Engineering alld Managemem. (pp. 1401-1424).

Clark, K. B., \& Baldwin, C. Y. (2000). Design Rules: The power of modularity. MIT Press.

Cusumano, M. A., \& Nobeoka, K. (1998). Thinking beyond lean: How multi-project management is transforming product development at Toyota and other companies. Free Press.

Ensign, P. C. (2004). A resource-based view of interrelationships among organizational groups in the diversified firm. Strategic Change, 13(3), 125-137.

Eppinger, S. D., \& Browning, T. R. (2012). Design structure matrix methods and applications. In Engineering systems. MIT Press. 
Dedicated vs. shared resources in organizations: Modifying the Design Structure Matrix (DSM) to support consolidation decisions

Flyvbjerg, B. (2008). Curbing Optimism Bias and Strategic Misrepresentation in Planning: Reference Class Forecasting in Practice. European Planning Studies, 16(1), 3-21. https://doi.org/10.1080/09654310701747936

Hill, C. W. L., Hitt, M. A., \& Hoskisson, R. E. (1992). Cooperative Versus Competitive Structures in Related and Unrelated Diversified Firms. Organization Science, 3(4), 501-521. https://doi.org/10.1287/orsc.3.4.501

Kilmann, R. H. (1983). The costs of organization structure: Dispelling the myths of independent divisions and organization-wide decision making. Accounting, Organizations and Society, 8(4), 341-357.

McCord and Eppinger, S. D., K. (1993). Managing the integration problem in concurrent engineering. Working Paper 3594,. MIT Sloan School of Management.

Micaëlli, J. P., Bonjour, É., \& Chiaberge, M. (2011). Are skill design structure matrices new tools for automotive design managers?. New Trends and Developments in Automotive Industry, 255-264.

Otto, K., Hölttä-Otto, K., Sanaei, R., \& Wood, K. L. (2020). Incorporating Field Effects into Functional Product-System Architecting Methods. Journal of Mechanical Design, Transactions of the ASME, 142(4).

Sanaei, R., Otto, K. N., Hölttä-Otto, K., \& Wood, K. L. (2016). Incorporating constraints in system modularization by interactive clustering of design structure matrices. Proceedings of the ASME Design Engineering Technical Conference, 2B-2016.

Sanchez, R. (1995). Strategic flexibility in product competition. Strategic Management Journal, 16(S1), 135-159.

Sharman, D. M., \& Yassine, A. A. (2004). Characterizing complex product architectures. Systems Engineering, 7(1), 35-60.

Teece, D. J. (1980). Economies of scope and the scope of the enterprise. Journal of Economic Behavior and Organization, 1(3), 223-247.

Thompson, J. D. (1967). Organizations in action: Social science bases of administrative theory. McGraw-Hill.

Urwick, L. (1937). Organization as a technical problem. In L. Gulick \& L. Urwick (Eds.), Papers on the Science of Administration. Fairfield: Augustus M. Kelley Publishers.

van Wijk, R., Jansen, J. J. P., \& Lyles, M. A. (2008). Inter- and Intra-Organizational Knowledge Transfer: A Meta-Analytic Review and Assessment of its Antecedents and Consequences. Journal of Management Studies, 45(4), 830-853.

Williamson, O. E. (1975). Markets and hierarchies: Analysis and antitrust implications. Free Press.

Worren, N., \& Pope, S. (2021). Connected by conflicting: Separating incompatible roles in organizations. Manuscript in Review.

Yu, T.-L., Yassine, A. A., \& Goldberg, D. E. (2007). An information theoretic method for developing modular architectures using genetic algorithms. Research in Engineering Design, 18(2), 91109.

Zhou, Y. M. (2013). Designing for Complexity: Using Divisions and Hierarchy, to Manage Complex Tasks. Organization Science, 24(2), 339-355.

Contact: Prof. Ali Yassine, Department of Industrial Engineering \& Management, Faculty of Engineering \& Architecture, American University of Beirut, ali.yassine@ aub.edu.lb 